\title{
Multiagent Route Choice Game for Transportation Engineering
}

\author{
Xuan Di, Henry X. Liu, and David M. Levinson
}

In undergraduate transportation engineering courses, traffic assignment is a difficult concept for instructors to teach and for students to learn because the concept involves advanced mathematical modeling and computations. A multiplayer game, called multiagent route choice, is designed to engage students in making route choices so that they can visualize how traffic gradually reaches a user equilibrium. In addition, the Braess paradox phenomenon, a concept not generally taught in undergraduate transportation courses, is embedded in the game for students to explore. A before-and-after comparison and a case-control study are performed to evaluate the effectiveness of the game as a curriculum tool. The impact of students' learning preferences is also investigated.

Civil engineering in general, and transportation engineering education in particular, has been evolving from traditional "chalk-andtalk" lectures to more problem- and project-based or game- and simulation-based learning (1-3).

Educational games and simulations have been used since the 1950s (2). Games and interactive simulations have been incorporated into transportation courses at the Transportation Engineering program at University of Minnesota, Twin Cities, for more than a decade. The Simulating Transportation for Realistic Engineering Education and Training (STREET) platform, developed by University of Minnesota researchers and sponsored by the National Science Foundation, integrates a series of projects composed of nine web-based simulation modules, which can be accessed at the website http://street.umn.edu/ (4). The ROAD (roadway online application for design) module is widely used for road design in undergraduate introductory courses. SONG (simulator of network growth) and ADAM (agent-based demand and assignment model) facilitate in-depth understanding of transportation network development and transportation systems planning $(5,6)$. In addition to STREET, researchers from the University of Minnesota used transportation-themed board games, such as Air Baron, Metro, Rail Tycoon, Empire Builder, and 1870, in undergraduate education. Huang and Levinson explored the effects of incorporating these board games into the curriculum and showed that they could enhance student learning in transportation planning (7).

Transportation planning, an important part of transportation engineering education, incorporates how traffic designers predict travel

X. Di, University of Michigan Transportation Research Institute, 2901 Baxter Road, Room 241, and H.X. Liu, 2320 George Granger Brown Memorial Laboratories, University of Michigan, 2350 Hayward Street, Ann Arbor, Ml 481092125. D. M. Levinson, Department of Civil, Environmental, and Geo-Engineering, University of Minnesota, Twin Cities, Pillsbury Drive, SE, Minneapolis, MN 55455. Corresponding author: X. Di, sharondi@umich.edu.

Transportation Research Record: Journal of the Transportation Research Board, No. 2480, Transportation Research Board, Washington, D.C., 2015, pp. 55-63. DOl: 10.3141/2480-07 demands and plan urban transportation networks so that the whole transportation system can be operated efficiently and effectively. Games, offering students hands-on experience, are able to help students gain an in-depth understanding of concepts and underlying theories in transportation planning.

Route choice (sometimes referred to as traffic assignment) describes the process by which travelers choose routes. Under assumptions such as that all users minimize the disutility of travel (usually taken to be minimizing travel time), route choice problems on networks generally result in a user equilibrium pattern of traffic, in which it is to no individual traveler's advantage to change routes if no one else does. User equilibrium is thus an emergent property of individual route choice behavior. To enhance students' learning of user equilibrium, an interactive game of the equilibrium-finding process is introduced. The game is called multiagent route choice (MARC) (downloadable from the website http://street.umn.edu/MARC.html). MARC engages students in the choice decision process and allows them to experience the equilibration process. It is hoped that the experience piques students' interest in learning and improves their understanding of the underlying equilibrium theory and the mathematical formulas involved.

The lecture on traffic assignment modeling should be accompanied by an important phenomenon, the Braess paradox (8), which states that building new roads does not necessarily improve traffic conditions. This concept is not usually taught in undergraduate classes because of its counterintuitive nature, but mastering it can facilitate economical transportation network planning and sustainable infrastructure investment. Moreover, the Braess paradox can enrich students' understanding of travel behavior theories and help them develop capabilities to apply those theories to real-world situations they might encounter as transportation planners. Many researchers have explored the existence of equilibrium or the Braess paradox behaviorally by recruiting volunteers to play a multiple-player game (9-13). However, instead of education, their goal was to study travelers' choice behavior. To engage students to discover this scientific phenomenon through the game, the Braess paradox is embedded in MARC.

In this paper, MARC will be introduced and the role of learning styles in adopting an interactive multiagent computer game as an education tool will be explored. MARC aims to benefit both students and instructors by making course materials easy and fun to learn for students and providing an opportunity to embed hands-on experiments and active learning strategies into curricula for instructors. The research questions of this study follow:

- Does MARC improve students' understanding of traffic assignment and the Braess paradox?

- Is MARC an effective tool in undergraduate transportation engineering courses?

- Which type of learners benefit more by playing MARC? 
In the next section, MARC is introduced and the undergraduate course in which the game was implemented is described. Then the statistical findings of the game from a before-and-after comparison and a case-control study are presented. These statistics show that the game improves students' understanding and is an effective education tool. Types of learners who benefit more from playing are also revealed. Students' feedback and comments on the game are presented in the following section. Then conclusions and lessons are summarized.

\section{GAME-BASED LEARNING}

\section{Learning Preferences}

Provided the same course curriculum, students with different learning styles benefit differently from playing games (5-7, 14). Kolb (14) identified experiential learning styles and proposed a four-stage learning cycle: concrete experience, reflective observation, abstract conceptualization, and active experimentation and four types of learning styles: diverging (concrete experience and reflective observation), assimilating (abstract conceptualization and reflective observation), converging (abstract conceptualization and active experimentation), and accommodating (concrete experience and active experimentation). For each learning style, different teaching strategies are needed. Diverging learners need hands-on exploration of a system; assimilating learners require accurate, organized delivery of information, prepared tutorials and exercises; converging learners learn effectively from interactive and computer-assisted instruction; and accommodating learners require independent discovery and active participation.

In this study, the impact of students' learning styles on learning consequences will be explored. Accordingly, the learning variables will be first elaborated (14):

1. Concrete experience (i.e., feeling). Learns from specific experiences and relating to people,

2. Reflective observation (i.e., watching). Observes before making a judgment by viewing the environment from different perspectives,

3. Abstract conceptualization (i.e., thinking). Uses logical analysis of ideas and acts on intellectual understanding of a situation, and

4. Active experimentation (i.e., doing). Achieves by influencing people and events through action.

The four learning styles are extended to be sensing (concrete, practical facts and procedure oriented) and intuitive (conceptual, innovative, oriented to theory and meaning); visual (prefer visual representations, such as charts) and verbal (prefer written or spoken explanations); active (doing) and reflective (thinking); sequential (linear, orderly, learn in small increments) and global (holistic, system thinkers, learn in large steps).

\section{Course Description}

Introduction to transportation engineering is the first and only required transportation engineering course for undergraduate students in the Department of Civil, Environmental, and Geo-Engineering at the University of Minnesota. It is taught every semester, with an average enrollment of 60 students (more in spring, fewer in fall). Registered students include sophomores, juniors, and some out-ofsequence seniors (6). This course usually contains two 2-h lectures and one recitation or computer lab each week. There are two or three lab or recitation sessions each week.

\section{Game Description}

Before the game was implemented, the four-step transportation planning model was introduced to students during lectures. The route choice model was discussed in detail and the concept of Wardrop user equilibrium was mentioned. The Braess paradox was not in the syllabus, so students were expected to discover it through the game. The paradox is also not described in the textbook Principles of Highway Engineering and Traffic Analysis (5th edition) (15) (which has been used in some semesters) or in the Fundamentals of Transportation wikibook provided to students (http://en.wikibooks.org/wiki /Fundamentals_of_Transportation). To help students understand better the concepts taught in the lecture, MARC was developed. The goals of the game are twofold:

- Demonstrate the Wardrop user equilibrium concept by letting students make route choices with other players simultaneously, through which equilibrium is gradually achieved. Gaming equilibration can strengthen understanding of the importance of equilibrium and motivate learning.

- Illustrate the Braess paradox phenomenon by letting students experience a change in travel time before and after a new link is added. Simulating the paradox can engage students to learn how to economically design transportation networks.

MARC is developed in the C\# language by using Windows Studio 2008. As a multiplayer game, MARC uses a client-server model. A terminal computer, serving as the client, provides an interface for a player to take action. These terminal user computers are connected to a server computer, and the decisions made at the terminal computers are sent to the server. The server collects data from each terminal (i.e., the identification of each player, the action the player takes, and some game-related information), stores and analyzes them in a database created in SQL Server 2005, and broadcasts the summary report to every terminal. After receiving the feedback from the server, players play the next round of the game.

MARC is used in the lab sessions of the course. At the beginning of the session, every player sits in front of a computer and receives playing instructions. Players are asked to log in and play two games. Each game includes two scenarios. In the first scenario, a small network contains two alternative routes connecting one origin-destination pair. In the second scenario, a new road is built so that there are three alternative routes. The difference between the two games is that in the first game, building a new road reduces everybody's travel time, but in the second game, the new road worsens system performance. Two scenarios from the first game are as follows: (a) Scenario 1 contains a small network with four links (see Figure 1a), and (b) Scenario 2 involves a new bridge being built between A and B (see Figure $1 b$ ).

In each scenario, a small imaginary network is presented, along with the flow-dependent travel time function of each link (see Figure 1c). All available routes are indicated in the route choice window. Each player is asked to choose one route traveling from $\mathrm{O}$ (origin) to $\mathrm{D}$ (destination). Each stage is repeated for 10 rounds to ensure that user equilibrium is reached. After all players submit their route choices, a summary of how many chose each route and the flowdependent travel time of each route are presented (see Figure 1d). Players adjust route choices in the next day's selection as the game continues. 


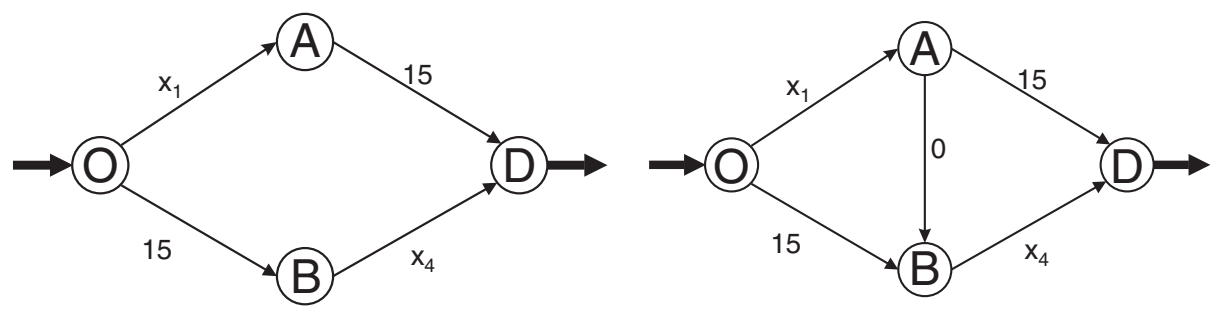

(a)

(b)

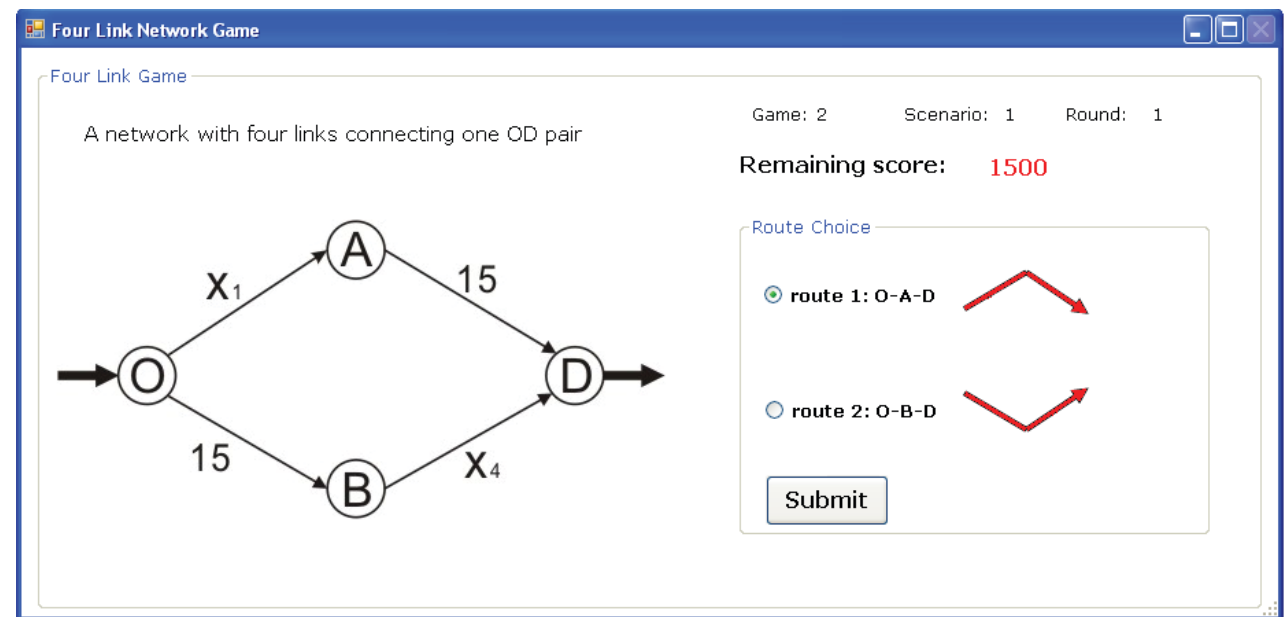

(c)

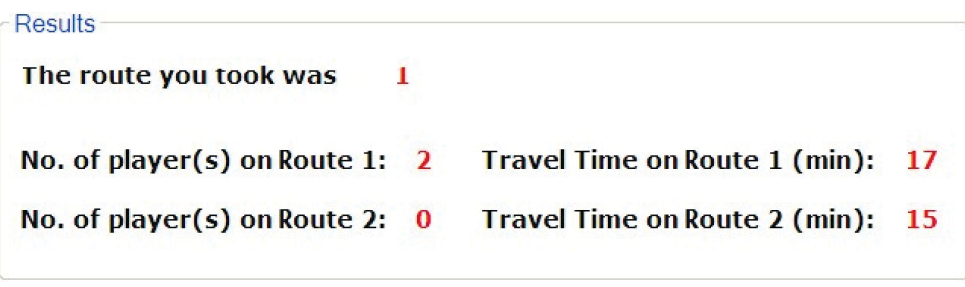

(d)

FIGURE 1 MARC interface: $(a)$ network illustration for Scenario $1,(b)$ network illustration for Scenario 2, $(c)$ route choice window, and (d) route choice results (no. = number).

The game session lasts about $40 \mathrm{~min}$. At the beginning of the game, each player receives a fixed number of points. To motivate players to minimize travel time, the travel time from each round is subtracted from a player's score. The player with the highest score wins the game.

\section{Game Implementation}

To ensure that educational goals can be achieved successfully, before students begin playing, they are asked to brainstorm factors that influence their route choices from home to school. This process helps them connect their own travel experiences with the classroom learning. Then students are told that their grades depend on how effectively they play the game, that is, how effectively they minimize travel time, which motivates them to choose routes like a real traveler. After playing the game, they reflect on the two games and share their findings with others. After they summarize key points of what they have learned from the game, their learning is reinforced with a video from the Public Broadcasting Service of the Braess paradox occurring in
Manhattan in New York City (http://www.pbs.org/america-revealed /teachers/lesson-plan/3/).

This game has been used for four semesters: spring 2012, fall 2012, fall 2013, and spring 2014. Descriptive statistics are presented in Table 1. One hundred seventy-eight students have played the game. Column $\mathrm{C} 1$ presents the number of players in each semester.

To test whether this computer game can actually improve students' understanding of traffic assignment and the Braess paradox, a beforeand-after comparison and a case-control study were conducted. In column $\mathrm{C} 2$, an $\mathrm{X}$ indicates whether the before-and-after study was performed in the associated semester. Because players were required to complete a survey before playing the game and another survey after playing the game, all were involved in the before-and-after study.

Columns C3 through C5 describe the case-control study. In column $\mathrm{C} 3$, the semester when a case-control study was implemented is indicated with an X. The case-control study was performed for spring 2012, fall 2012, and fall 2013, and 124 players participated. In those three semesters, students were randomly assigned to a case group or a control group. This study was possible because there were multiple lab sessions each week. In one or two sessions the game was used (i.e., 
TABLE 1 Game Implementation Statistics

\begin{tabular}{lcccccc}
\hline & & & & \multicolumn{2}{l}{$\begin{array}{l}\text { Number of } \\
\text { Students }\end{array}$} & \\
\cline { 5 - 6 } Semester & $\begin{array}{l}\text { Number } \\
\text { of Players } \\
\text { (C1) }\end{array}$ & $\begin{array}{l}\text { Before-and- } \\
\text { After Study } \\
\text { (C2) }\end{array}$ & $\begin{array}{l}\text { Case-Control } \\
\text { (C3) }\end{array}$ & $\begin{array}{l}\text { Case } \\
\text { (C4) }\end{array}$ & $\begin{array}{l}\text { Control } \\
\text { (C5) }\end{array}$ & $\begin{array}{l}\text { Transportation } \\
\text { Background } \\
\text { (C6) }\end{array}$ \\
\hline Spring 2012 & 68 & $\mathrm{X}$ & $\mathrm{X}$ & 48 & 20 & na \\
Fall 2012 & 30 & $\mathrm{X}$ & $\mathrm{X}$ & 19 & 11 & $\mathrm{X}$ \\
Fall 2013 & 26 & $\mathrm{X}$ & $\mathrm{X}$ & 17 & 9 & $\mathrm{X}$ \\
Spring 2014 & 54 & $\mathrm{X}$ & na & na & na & X \\
Total students & 178 & 178 & 124 & 84 & 40 & 110 \\
\hline
\end{tabular}

NOTE: $\mathrm{X}=$ performed associated semester; na $=$ not applicable.

case group or play group); in the remaining sessions it was not (i.e., control group or no-play group). Students in the play group played the game and filled in the postsurvey. Meanwhile, those from the no-play group did not play MARC. Instead, they played ADAM (downloadable from http://street.umn.edu/), which was also designed to enhance students' understanding of traffic assignment. Then they were asked to answer the same set of questions about traffic assignment and the Braess paradox as the play group. (The no-play group played MARC in a subsequent lab session to ensure fairness in the course outcome; the group also completed the postsurvey about their opinions on the use of games.) Columns $\mathrm{C} 4$ and $\mathrm{C} 5$ indicate the number of cases and controls for each semester. There were 84 cases and 40 controls.

Column C6 indicates the semesters when the transportation background survey was conducted. In spring 2012, these questions were not included. The transportation background survey includes students' self-evaluation of their understanding of transportation knowledge; the transportation background questions are included in both the pre- and postsurveys.

\section{GAME STATISTICAL FINDINGS}

\section{Pre- and Postsurveys}

Before and after game play, students are asked to complete surveys (accessible from the website http://street.umn.edu/MARC/Pre_Post _Survey.pdf). The presurvey consists of four sections: players' demographic information, transportation background, learning style, and transportation understanding. The postsurvey is mainly designed to collect students' opinions about the game and to assess whether their understanding has improved after playing the game. There are three sections in the postsurvey: game evaluation, transportation background, and transportation understanding. See Tables 2 and 3 for descriptive statistics of pre- and postsurvey results.

The research goals were assessed with the data collected from the pre- and postsurveys.

\section{Correlations Between Demographic and Learning Preference Statistics}

To facilitate the quantitative analysis, qualitative variables need to be first coded as numerical values. Gender is coded as 0 if the player is female and 1 otherwise. Learning style variables (feeling, watching, thinking, doing) are coded binary in regression. For example, feeling $=0$ represents that the subject does not prefer learning by concrete experience; otherwise feeling $=1$. Learning preference variables (sensing, visual, active, sequential) have five scales. For example, highly sensing, moderately sensing, mildly sensing or intuitive, moderately intuitive, and highly intuitive are coded as 2, $1,0,-1$, and -2 , respectively. The higher the value, the more sensing and less intuitive the subject.

Correlations between age, gender, and learning characteristics (presented in Table 4) are calculated. Age does not have strong

TABLE 2 Descriptive Statistics of Presurvey Results

\begin{tabular}{|c|c|c|c|}
\hline Variable & Level & Frequency & Percentage \\
\hline \multirow[t]{2}{*}{ Gender } & Male & 134 & 75.3 \\
\hline & Female & 44 & 24.7 \\
\hline \multirow[t]{4}{*}{$\begin{array}{l}\text { Learning } \\
\text { preference }\end{array}$} & $\begin{array}{l}\text { Concrete experience } \\
\text { (feeling) }\end{array}$ & 66 & 37.1 \\
\hline & $\begin{array}{l}\text { Reflective observation } \\
\text { (watching) }\end{array}$ & 101 & 56.7 \\
\hline & $\begin{array}{l}\text { Abstract conceptual- } \\
\text { ization (thinking) }\end{array}$ & 51 & 28.7 \\
\hline & $\begin{array}{l}\text { Active experimenta- } \\
\text { tion (doing) }\end{array}$ & 135 & 75.8 \\
\hline \multirow[t]{5}{*}{ Sensing } & Highly sensing & 27 & 15.2 \\
\hline & Moderately sensing & 82 & 46.1 \\
\hline & $\begin{array}{l}\text { Mildly sensing or } \\
\text { intuitive }\end{array}$ & 36 & 20.2 \\
\hline & Moderately intuitive & 22 & 12.4 \\
\hline & Highly intuitive & 11 & 6.2 \\
\hline \multirow[t]{5}{*}{ Visual } & Highly visual & 59 & 33.1 \\
\hline & Moderately visual & 76 & 42.7 \\
\hline & Mildly visual or verbal & 25 & 14.0 \\
\hline & Moderately verbal & 16 & 9.0 \\
\hline & Highly verbal & 2 & 1.1 \\
\hline \multirow[t]{5}{*}{ Active } & Highly active & 52 & 29.2 \\
\hline & Moderately active & 69 & 38.8 \\
\hline & $\begin{array}{l}\text { Mildly active or } \\
\text { reflective }\end{array}$ & 35 & 19.7 \\
\hline & Moderately reflective & 18 & 10.1 \\
\hline & Highly reflective & 4 & 2.2 \\
\hline \multirow[t]{5}{*}{ Sequential } & Highly sequential & 35 & 19.7 \\
\hline & Moderately sequential & 70 & 39.3 \\
\hline & $\begin{array}{l}\text { Mildly sequential or } \\
\text { global }\end{array}$ & 42 & 23.6 \\
\hline & Moderately global & 24 & 13.5 \\
\hline & Highly global & 7 & 3.9 \\
\hline
\end{tabular}

NotE: Participant age: minimum $=18$ years $;$ maximum $=50$ years; mean $=21.7$ years; and standard deviation $=3.9$. 
TABLE 3 Descriptive Statistics of Postsurvey Results

\begin{tabular}{|c|c|c|c|c|c|c|}
\hline Variable & Mean & SD & Median & Level & Frequency & Percentage \\
\hline Ease level & 2.0 & 1.0 & 2 & $\begin{array}{r}1 \\
2 \\
3 \\
4 \\
5 \\
\mathrm{NA}\end{array}$ & $\begin{array}{r}60 \\
62 \\
42 \\
12 \\
1 \\
1\end{array}$ & $\begin{array}{r}33.7 \\
34.8 \\
23.6 \\
6.7 \\
0.6 \\
0.6\end{array}$ \\
\hline $\begin{array}{l}\text { Satisfaction } \\
\text { level }\end{array}$ & 3.2 & 1.1 & 3 & $\begin{array}{r}1 \\
2 \\
3 \\
4 \\
5 \\
\mathrm{NA}\end{array}$ & $\begin{array}{r}14 \\
32 \\
53 \\
62 \\
16 \\
1\end{array}$ & $\begin{array}{r}7.8 \\
18.0 \\
29.8 \\
34.8 \\
9.0 \\
0.6\end{array}$ \\
\hline $\begin{array}{l}\text { Stimulation } \\
\text { level }\end{array}$ & 3.2 & 1.1 & 3 & $\begin{array}{r}1 \\
2 \\
3 \\
4 \\
5 \\
\mathrm{NA}\end{array}$ & $\begin{array}{r}12 \\
28 \\
59 \\
60 \\
18 \\
1\end{array}$ & $\begin{array}{r}6.7 \\
15.7 \\
33.1 \\
33.7 \\
10.2 \\
0.6\end{array}$ \\
\hline $\begin{array}{l}\text { Enhancement } \\
\text { level }\end{array}$ & 3.6 & 1.1 & 4 & $\begin{array}{r}1 \\
2 \\
3 \\
4 \\
5 \\
\mathrm{NA}\end{array}$ & $\begin{array}{r}10 \\
13 \\
50 \\
73 \\
31 \\
1\end{array}$ & $\begin{array}{r}5.6 \\
7.3 \\
28.1 \\
41.0 \\
17.4 \\
0.6\end{array}$ \\
\hline $\begin{array}{l}\text { Motivation } \\
\text { level }\end{array}$ & 3.7 & 1.0 & 4 & $\begin{array}{r}1 \\
2 \\
3 \\
4 \\
5 \\
\mathrm{NA}\end{array}$ & $\begin{array}{r}6 \\
11 \\
45 \\
73 \\
42 \\
1\end{array}$ & $\begin{array}{r}3.4 \\
6.2 \\
25.3 \\
41.0 \\
23.5 \\
0.6\end{array}$ \\
\hline $\begin{array}{l}\text { Effectiveness } \\
\text { level }\end{array}$ & 3.8 & 1.0 & 4 & $\begin{array}{r}1 \\
2 \\
3 \\
4 \\
5 \\
\text { NA }\end{array}$ & $\begin{array}{r}8 \\
11 \\
31 \\
88 \\
39 \\
1\end{array}$ & $\begin{array}{r}4.5 \\
6.2 \\
17.4 \\
49.4 \\
21.9 \\
0.6\end{array}$ \\
\hline
\end{tabular}

NotE: $\mathrm{SD}=$ standard deviation; $\mathrm{NA}=$ not available (one player's data missing).

TABLE 4 Correlations Between Demographic and Learning Characteristics

\begin{tabular}{lrrrrrrrrrr}
\hline Variable & Age & Gender & Feeling & Thinking & Doing & Watching & Sensing & Visual & Active & Sequential \\
\hline Age & 1.0 & 0.1 & 0.0 & -0.1 & -0.1 & -0.1 & 0.1 & 0.1 & -0.0 & -0.1 \\
Gender & 0.1 & 1.0 & -0.0 & 0.1 & -0.2 & 0.1 & -0.2 & -0.0 & -0.1 & -0.1 \\
Feeling & 0.0 & -0.0 & 1.0 & 0.0 & 0.1 & -0.1 & 0.1 & 0.1 & 0.1 & -0.0 \\
Thinking & -0.1 & 0.1 & 0.0 & 1.0 & -0.1 & 0.2 & -0.2 & -0.2 & -0.3 & -0.2 \\
Doing & -0.1 & -0.1 & -0.2 & 0.1 & 1.0 & -0.0 & 0.1 & 0.2 & 0.4 & -0.1 \\
Watching & -0.1 & 0.1 & -0.1 & 0.2 & -0.0 & 1.0 & 0.2 & -0.0 & -0.0 & 0.1 \\
Sensing & 0.1 & -0.2 & 0.1 & -0.2 & 0.1 & 0.2 & 1.0 & 0.1 & 0.3 & 0.2 \\
Visual & 0.1 & -0.0 & 0.1 & -0.2 & 0.2 & -0.0 & 0.1 & 1.0 & 0.2 & 0.0 \\
Active & -0.0 & -0.1 & 0.1 & -0.3 & 0.4 & -0.0 & 0.3 & 0.2 & 1.0 & 0.1 \\
Sequential & -0.1 & -0.1 & -0.0 & -0.2 & -0.1 & 0.1 & 0.2 & 0.0 & 0.1 & 1.0 \\
\hline
\end{tabular}


correlation with any learning characteristics. Males are more active than females and prefer concrete, fact-oriented learning over conceptual learning. Of all learning styles, students who identify their learning styles as active learn by active experimentation instead of abstract conceptualization and are thus more sensing (i.e., preferring concrete, fact-oriented learning).

\section{Play Versus No-Play: Do Players Benefit?}

As indicated in Table 1, the case-control study was performed in spring 2012, fall 2012, and fall 2013. There are 84 cases and 40 controls, and thus 124 players. The goal is to test whether playing MARC enhances understanding of the Braess paradox.

The hypothesis is that students who played the game have better understanding of the Braess paradox. This hypothesis is tested on the basis of students' answers to a question on transportation understanding in both surveys: "generally speaking, given the total traffic demand on the network is fixed, after a new road is added, how will everyone's travel time change and why?"

The correct answer is that it depends. The reason is that everybody's travel time may improve or remain the same if the Braess paradox does not happen and will worsen if the paradox does happen.

The play group participated in the game play and experienced both travel time increase and decrease with the addition of a link. The noplay group was given the same set of networks used in the game but was asked to solve the equilibrium travel time. Then both groups answered the same question in the postsurvey.

Students' performance was evaluated by both their choices and reasoning. If a student's answer to the transportation understanding question is correct but the explanation is wrong, the understanding of the Braess paradox is still treated as incorrect.

In the presurvey, $13.8 \%$ students from the no-play group and $24.2 \%$ from the play group realized that travel time may increase or decrease or stay the same after a new link is added. The remaining students thought only one consequence could happen or gave wrong explanations of their choices.

The postsurvey results show that 12 students (four fewer than in the presurvey) from the no-play group and 48 (18 more) from the play group were able to identify the Braess paradox.

To further quantify the impact of adopting MARC as an educational tool, a regression analysis is used. Let $Y$ be the response variable, representing whether a student's answer to the Braess paradox question in the postsurvey is correct; it equals zero if incorrect and one if correct. Let play be the explanatory variable, indicating whether the student played the game before answering the question; it equals zero if the student belongs to the no-play group and one otherwise. The above hypothesis is equivalent to testing the relationship between $Y$ and play. Because the response variable carries a value of either zero or one, the logistic regression is adopted:
TABLE 5 Logistic Regression Coefficients

\begin{tabular}{lcccc}
\hline \multirow{4}{*}{ Covariate } & Estimate & Standard Error & Z-Value & $p$-Value \\
\cline { 2 - 5 } & -0.85 & 0.35 & -2.46 & $.01^{*}$ \\
(Intercept) & 1.14 & 0.41 & 2.77 & $.01^{* *}$ \\
\hline
\end{tabular}

*Statistically significant at 5\%; **statistically significant at $1 \%$.

$\log \frac{P(Y=1)}{P(Y=0)}=\beta_{0}+\beta_{1}$ play

where $\beta_{0}$ and $\beta_{1}$ are regression coefficients that need to be estimated.

The logistic regression coefficients and the goodness-of-fit results are presented in Tables 5 and 6 . The chi-square goodnessof-fit test shows that the hypothesis that the above model fits data well cannot be rejected at the significance level of $1 \%$. The estimated increase in odds of improvement is $3.1\left(=e^{1.14}\right)$. In other words, the likelihood that game players understand the impact of adding a new road is three times more than that of nonplayers. In conclusion, after playing MARC, students understood the Braess paradox better.

\section{Innovative Teaching: Who Thinks the Computer Game Is an Effective Curriculum Tool?}

After playing the game, students were asked to rate the effectiveness of this computer game as a curriculum tool on a scale of 1 to 5: not effective at all to very effective.

The hypothesis is as follows: among those who played the game, whether the computer game is considered to be an effective learning tool is influenced by students' learning preferences.

Effectiveness of the computer game is represented by an ordinal variable with values of $1,2,3,4,5$. Ordinal data are the categorical data in which there is logical ordering represented by ordered numeric scales. To test the hypothesis, ordinal logistic regression needs to be adopted. In ordinal logistic regression, a proportional odds assumption is made that coefficients describing the relationship between neighboring categories of the response variable are the same. Because of the same relationship between all pairs of groups, only one set of coefficients is needed.

Let $Y$ be the response variable, representing the scale of effectiveness (i.e., $Y=1,2,3,4,5)$. The $R$ statistical package ordered logistic or probit regression (polr) (http://stat.ethz.ch/R-manual/R-patched /library/MASS/html/polr.html) is adopted to study the relationship between effectiveness and players' age and their learning character-

TABLE 6 Goodness-of-Fit Test

\begin{tabular}{lccccc}
\hline Covariate & $\begin{array}{l}\text { Degrees of } \\
\text { Freedom }\end{array}$ & $\begin{array}{l}\text { Residual } \\
\text { Deviance }\end{array}$ & $\begin{array}{l}\text { Degrees of } \\
\text { Freedom }\end{array}$ & $\begin{array}{l}\text { Residual } \\
\text { Deviance }\end{array}$ & $\operatorname{Pr}(>$ Chi $)$ \\
\hline Null & & & 123 & 171.87 & \\
Play & 1 & 6.69 & 122 & 165.18 & $.01^{*}$ \\
\hline * = statistically significant at $1 \%$ level. & & &
\end{tabular}


istics (i.e., feeling, thinking, doing, watching, sensing, visual, active, sequential):

$$
\begin{array}{r}
\log \frac{P(Y=i+1)}{P(Y=i)}=\beta_{0}+\beta_{1} \text { age }+\sum_{n=2}^{9} \beta_{n} \text { learning variable }{ }_{n} \\
\quad i=1,2,3,4
\end{array}
$$

where $\beta_{n}(n=0, \ldots, 9)$ are regression coefficients that need to be estimated. Estimated regression coefficients are presented in Table 7.

The interpretation of coefficients in ordinal logistic regression is

1. For the continuous variable age, when a student's age increases by one, the odds that the student thinks the game is very effective versus less effective are $1.0\left(=e^{-0.00}\right)$ times lower, given that all of the other variables in the model are held constant. Thus, age is not clearly related to the effectiveness level.

2. For binary variables (i.e., feeling, thinking, doing, watching), for example, given one unit increase in watching (i.e., going from 0 to 1$)$, the odds that the player thinks the game is very effective versus less effective are $0.4\left(=e^{-0.89}\right)$ times lower. Likewise, the odds of the combined middle and high effectiveness versus low category are 0.4 times lower, given that all of the other variables in the model are held constant.

3. For ordinal variables (i.e., sensing, active, visual, sequential), for example, given one unit increase in active (i.e., going from moderately active to highly active), the odds that the player thinks the game is very effective versus less effective are multiplied by $1.5\left(=e^{0.37}\right)$.

An inspection of $p$-values reveals that thinking, watching, visual, and active are significant at the $10 \%$ significance level. The coefficients before thinking, visual, and active are positive, showing that when a player prefers abstract conceptualization (thinking), learning by visual presentation, and doing, the odds of viewing the game as an effective learning tool are greater. The coefficient before watching is negative, showing that when a player prefers reflective observation (watching), the odds of viewing the game as an effective learning tool are lower. Given a player who prefers reflective observation (watching) and another player at the same age who is not in the stage of reflective observation, the odds of treating this game as an effec-

TABLE 7 Ordinal Logit Model Regression Coefficients for Innovative Teaching

\begin{tabular}{lrcrl}
\hline Variable & Value & $\begin{array}{l}\text { Standard } \\
\text { Error }\end{array}$ & $t$-Value & $p$-Value \\
\hline Age & -0.00 & 0.04 & -0.01 & .99 \\
Feeling & 0.05 & 0.30 & 0.17 & .87 \\
Thinking & 0.66 & 0.37 & 1.79 & $.07^{*}$ \\
Doing & 0.05 & 0.38 & 0.13 & .90 \\
Watching & -0.89 & 0.31 & -2.86 & $.00^{* * *}$ \\
Sensing & 0.06 & 0.16 & 0.36 & .72 \\
Visual & 0.46 & 0.16 & 2.82 & $.00^{* * *}$ \\
Active & 0.37 & 0.17 & 2.19 & $.03^{* *}$ \\
Sequential & -0.15 & 0.15 & -1.01 & .31 \\
\hline
\end{tabular}

$* p<.1 . ; * * p<.05 . ; * * * p<.01$. tive learning tool are lower. Those in the stage of reflective observation learning do not like exploring a system randomly. Instead, they want instructors to give them accurate information they should know and get correct answers to problems (14). However, playing computer games requires players to explore information on their own, which makes them feel uncomfortable in learning.

\section{Before and After: Whose Understanding Is Improved Through Playing the Game?}

The before-and-after study was performed for all four semesters, with 178 players (see Table 1). The hypothesis is as follows: the game-based curriculum improved students' transportation knowledge.

This hypothesis was tested on the basis of students' subjective evaluation of their understanding of transportation in pre- and postsurveys. The definitions of students who improved and did not improve their understanding through playing the game are as follows:

- Students whose understanding improved answered the transportation understanding question incorrectly in the presurvey but correctly in the postsurvey.

- Students whose understanding did not improve answered the transportation understanding question incorrectly in the presurvey and the postsurvey.

Of 178 participants, 55 students did not improve their answers to the question in the postsurvey, whereas 42 students did. Twenty students gave the correct answer in the presurvey but the wrong answer in the postsurvey, and 61 students answered the question correctly in both surveys. In the subsequent analysis, only those who did not improve (nonimprovers) and those who did improve (improvers) will be considered, so there are 97 subjects.

The following are summaries inferred from students' evaluations:

1. In general, students' understanding of transportation is improved through playing the game. The mean and the median are higher in the postsurvey than in the presurvey for both those who improved and those who did not improve, and the standard deviations are lower or remain the same.

2. Before playing the game, improvers had a better understanding of transportation than nonimprovers in every category except in practical issues and in opinions on transportation network planning and deployment. In these two categories, nonimprovers had slightly higher values than improvers.

3. After playing the game, nonimprovers had a better understanding of transportation in most categories than improvers, except in traffic assignment.

4. In the categories of transportation network planning and transportation network deployment, improvers have a better understanding than nonimprovers before playing the game but not after. The ability of improvers to form opinions on network planning and deployment is not as good as the ability of nonimprovers before playing the game, but it is better after. Improvers' understanding of practical issues is not as good as the understanding of nonimprovers before or after playing the game. Improvers' understanding of traffic assignment is better than that of nonimprovers both before and after.

In students' evaluation of their ability to form opinions about transportation network planning and deployment, the mean of the 
TABLE 8 Descriptive Statistics of Understanding

\begin{tabular}{|c|c|c|c|c|c|c|}
\hline Category & Group & Survey & Mean & $\mathrm{SD}$ & Median & $\begin{array}{l}\text { Paired } t \text {-Test } \\
p \text {-Value }\end{array}$ \\
\hline Transportation planning & $\begin{array}{l}\text { Improver } \\
\text { Nonimprover }\end{array}$ & $\begin{array}{l}\text { Before } \\
\text { After } \\
\text { Before } \\
\text { After }\end{array}$ & $\begin{array}{l}3.3 \\
3.6 \\
2.9 \\
3.7\end{array}$ & $\begin{array}{l}0.8 \\
0.6 \\
0.8 \\
0.7\end{array}$ & $\begin{array}{l}3 \\
4 \\
3 \\
4\end{array}$ & $\begin{array}{l}.01 * * \\
.00 * * *\end{array}$ \\
\hline $\begin{array}{l}\text { Transportation network } \\
\text { deployment }\end{array}$ & $\begin{array}{l}\text { Improver } \\
\text { Nonimprover }\end{array}$ & $\begin{array}{l}\text { Before } \\
\text { After } \\
\text { Before } \\
\text { After }\end{array}$ & $\begin{array}{l}2.8 \\
3.5 \\
2.5 \\
3.5\end{array}$ & $\begin{array}{l}0.8 \\
0.6 \\
0.9 \\
0.9\end{array}$ & $\begin{array}{l}3 \\
3.5 \\
3 \\
4\end{array}$ & $\begin{array}{l}.00 * * * \\
.00 * * *\end{array}$ \\
\hline $\begin{array}{l}\text { Opinions on network } \\
\text { planning and deployment }\end{array}$ & $\begin{array}{l}\text { Improver } \\
\text { Nonimprover }\end{array}$ & $\begin{array}{l}\text { Before } \\
\text { After } \\
\text { Before } \\
\text { After }\end{array}$ & $\begin{array}{l}3.2 \\
3.7 \\
3.3 \\
3.6\end{array}$ & $\begin{array}{l}0.9 \\
0.5 \\
1.0 \\
0.7\end{array}$ & $\begin{array}{l}3 \\
4 \\
3.5 \\
4\end{array}$ & $\begin{array}{l}.05 * \\
.00 * * * \\
.00 * * *\end{array}$ \\
\hline Practical issues & $\begin{array}{l}\text { Improver } \\
\text { Nonimprover }\end{array}$ & $\begin{array}{l}\text { Before } \\
\text { After } \\
\text { Before } \\
\text { After }\end{array}$ & $\begin{array}{l}3.1 \\
3.6 \\
3.2 \\
3.8\end{array}$ & $\begin{array}{l}0.9 \\
0.6 \\
1.0 \\
0.7\end{array}$ & $\begin{array}{l}3 \\
4 \\
3 \\
4\end{array}$ & $\begin{array}{l}.00 * * * \\
.00 * * *\end{array}$ \\
\hline Traffic assignment & $\begin{array}{l}\text { Improver } \\
\text { Nonimprover }\end{array}$ & $\begin{array}{l}\text { Before } \\
\text { After } \\
\text { Before } \\
\text { After }\end{array}$ & $\begin{array}{l}3.0 \\
4 \\
2.8 \\
3.8\end{array}$ & $\begin{array}{l}0.7 \\
0.6 \\
1.0 \\
0.8\end{array}$ & $\begin{array}{l}3 \\
4 \\
3 \\
4\end{array}$ & $\begin{array}{l}.00 * * * \\
.00 * * *\end{array}$ \\
\hline
\end{tabular}

$*$ Statistically significant at $5 \%$ level; $* *$ statistically significant at $1 \%$ level; ***statistically significant at .1\% level.

improvers' evaluation distribution in the presurvey is lower than that of nonimprovers (see Table 8). In the postsurvey, the mean shifts to the right of that of nonimprovers, meaning that improvers' ability to form opinions about transportation network planning and deployment is much more enhanced than nonimprovers' through game play. After playing the game, improvers' understanding and ability to apply what they have learned from the game to real problems is better.

To further test the hypothesis quantitatively that both improvers' and nonimprovers' knowledge is enhanced after playing the game, a group of paired $t$-tests were performed to show whether the means of the subjective evaluation values in the presurvey are less than those in the postsurvey. The $p$-values are listed in the last column of Table 8 . The category with a $p$-value well below .05 indicates that researchers can favor the alternative hypothesis that the game has made substantial improvements in both improvers and nonimprovers. Test results indicate that the understanding of both improvers and nonimprovers is enhanced, with the exception of the opinions of nonimprovers on planning and deployment.

\section{Enhanced Knowledge Level: Who Benefits More?}

In the postsurvey, students were asked to self-evaluate whether their learning about user equilibrium and the Braess paradox was enhanced by playing the game. They were asked to respond on a scale of 1 to 5 (the greater the value, the more their learning was enhanced).

The hypothesis is as follows: among those who played the game, students' age and their learning preference influence how much they would benefit from the game.

The ordinal logistic regression with predictors of age and all learning variables was tried, but only age and sequential were significant. When a student's age moves from 18 to 19 , the odds of moving from low to middle or high categories of enhancement (or from middle categories to high) is multiplied by $0.9\left(=e^{-0.07}\right)$. For one unit increase in sequential (e.g., going from moderately sequential to highly sequential), the odds of high enhancement versus the combined middle and low categories are 0.8 lower, given that all of the other variables in the model are held constant. In other words, for a student who prefers holistic and systematic learning in large steps, knowledge is more likely enhanced through playing the game.

\section{STUDENTS' FEEDBACK FROM THE GAME}

\section{Quantitative Assessment}

After playing the game, all players were asked to assess the easiness and effectiveness of the game on a scale from 1 to 5 (the greater the value, the more difficult or effective the game). The results are presented in Table 3. The median ease level is 2 , so more than half the players think this game is relatively easy, which matches the design goal. The median effectiveness level is 4 , meaning half the students consider this computer game a very effective curriculum tool.

\section{Qualitative Assessment}

In the postsurvey, feedback was collected from students about their experiences playing this game and their opinions on the Braess paradox scenario. As an aid in delivering formal lectures, students commented that this game is "essential to all students to have a good idea of the equations that we are using and how they are derived" and "helped me understand some of the assumptions that go into deriving those equations." Regarding the hands-on experience offered by the game, students commented that the game "was very helpful and would be helpful as a curriculum tool . . . you can visualize easily what is taking place and how it is working ... seeing how it can supplement how we learn is useful ... working on computer games allows for repetition, doing, and visualizing."

After witnessing the equilibration process in the course of route choice decision making, students found that "the longer you play 
each game, the closer the values get to reaching equilibrium." In addition, some students discovered the connection between route choice and game theory: "my choice isn't the only thing that factors into my score; it also has to do with what everyone around me is doing." Some also tried to interpret the user equilibrium from the behavioral perspective: "everyone may switch routes, which will increase travel time because we are all selfish."

By playing the Braess paradox game, students realized that "adding a new route will not always fix traffic issues." Some even learned the lesson about decision making in transportation network planning: "traffic is very fickle and dynamic; it needs to be studied closely before anything can be done to influence it without running the risk of overcompensating." Moreover, "if everyone had been more focused on maintaining a minimum average travel time and less focused on decreasing their own travel time," the Braess paradox might not happen. This comment further implied that some players were capable of discovering the real reason behind the occurrence of the Braess paradox and even managed to identify the concept of social optimality.

\section{CONCLUSION AND FUTURE RESEARCH}

This paper introduces MARC, a game developed for undergraduate transportation engineering education. The game benefits students' learning about user equilibrium and the Braess paradox. The statistical results show that this game supplements regular lectures, enhances student learning, and is an effective education tool.

There are still some technical complexities in the game, mainly because it is a multiplayer game instead of a stand-alone one. The aim is to popularize it as a web-based game, so that educators from other institutes can access it and apply it more easily to classroom teaching.

More scenarios need to be created for this platform. For example, real-time traffic information can be displayed to players to test its impact on players' reactions. This information can help students learn how intelligent transportation systems affect driver behavior and redistribute traffic patterns. Road toll charges can also be imposed to certain links to demonstrate to students the role of tolls in transportation operation and management.

\section{REFERENCES}

1. Mills, J.E., and D.F. Treagust. Engineering Education: Is ProblemBased or Project-Based Learning the Answer? Australasian Journal of Engineering Education, Vol. 3, No. 2, 2003.
2. Gredler, M.E. Educational Games and Simulations: A Technology in Search of a (Research) Paradigm. In The Handbook of Research for Educational Communications and Technology (D. H. Jonassen, ed.), Simon and Schuster Macmillan, New York, 1996, pp. 521-540.

3. Ebner, M., and A. Holzinger. Successful Implementation of UserCentered Game Based Learning in Higher Education: An Example from Civil Engineering. Computers \& Education, Vol. 49, No. 3, 2007 pp. 873-890.

4. Liao, C.-F., H.X. Liu, and D. M. Levinson. Simulating Transportation for Realistic Engineering Education and Training: Engaging Undergraduate Students in Transportation Studies. In Transportation Research Record: Journal of the Transportation Research Board, No. 2109, Transportation Research Board of the National Academies, Washington, D.C., 2009, pp. 12-21.

5. Chen, W., and D. M. Levinson. Effectiveness of Learning Transportation Network Growth Through Simulation. Journal of Professional Issues in Engineering Education and Practice, Vol. 132, No. 1, 2006, pp. 29-41.

6. Zhu, S., F. Xie, and D. M. Levinson. Enhancing Transportation Education Through Online Simulation Using an Agent-Based Demand and Assignment Model. Journal of Professional Issues in Engineering Education and Practice, Vol. 137, No. 1, 2011, pp. 28-45.

7. Huang, A., and D. Levinson. To Game or Not to Game: Teaching Transportation Planning with Board Games. In Transportation Research Record: Journal of the Transportation Research Board, No. 2307 Transportation Research Board of the National Academies, Washington, D.C., 2012, pp. 141-149.

8. Braess, D. Ber ein Paradoxon aus der Verkehrsplanung. Unternehmensforschung, Vol. 12, 1969, pp. 258-268.

9. Mahmassani, H.S., and D. G. Stephan. Experimental Investigation of Route and Departure Time Choice Dynamics of Urban Commuters. In Transportation Research Record 1203, TRB, National Research Council, Washington, D.C., 1988, pp. 69-84.

10. Mahmassani, H.S., and Y.-H. Liu. Dynamics of Commuting Decision Behaviour Under Advanced Traveller Information Systems. Transportation Research Part C, Vol. 7, No. 2-3, 1999, pp. 91-107.

11. Rapoport, A., T. Kugler, S. Dugar, and E. J. Gisches. Choice of Routes in Congested Traffic Networks: Experimental Tests of the Braess Paradox. Games and Economic Behavior, Vol. 65, No. 2, 2009, pp. 538-571.

12. Schneider, K., and J. Weimann. Against All Odds: Nash Equilibria in a Road Pricing Experiment. In Human Behaviour and Traffic Networks, Springer, Berlin, 2004, pp. 133-153.

13. Selten, R., M. Schreckenberg, T. Chmura, T. Pitz, S. Kube, S. F. Hafstein, R. Chrobok, A. Pottmeier, and J. Wahle. Experimental Investigation of Day-to-Day Route-Choice Behavior and Network Simulations of Autobahn Traffic in North Rhine-Westphalia. In Human Behavior and Traffic Networks. Springer, Berlin, 2004, pp. 1-21.

14. Kolb, D.A. Experiential Learning: Experience as the Source of Learning and Development. Prentice Hall, Englewood Cliffs, N.J., 1984.

15. Mannering, F., and S. Washburn. Principles of Highway Engineering and Traffic Analysis, 5th ed. John Wiley \& Sons, New York, 2012.

The Standing Committee on Transportation Education and Training peer-reviewed this paper. 